\title{
EMPLOYMENT AMONG USERS OF A MEDICALLY SUPERVISED SAFER INJECTION FACILITY
}

\author{
Lindsey Richardson ${ }^{1,3}$ \\ Evan Wood ${ }^{1,2}$ \\ Ruth Zhang ${ }^{1}$ \\ Julio Montaner ${ }^{1,2}$ \\ Mark Tyndall ${ }^{1,2}$ \\ Thomas Kerr ${ }^{1,2}$
}

1. British Columbia Centre for Excellence in HIV/ AIDS, St. Paul's Hospital, 608-1081 Burrard Street, Vancouver, BC, Canad a, V6Z 1Y6

2. Department of Medicine, University of British Colu mbia

3. Department of Sociology, Oxford University, Manor Road Building, Manor Road, Oxford, UK, OX13UQ

Send correspondence to: Thom as Kerr, $\mathrm{PhD}$

BC Centre for Excellence in HIV/ AIDS

608-1081 Burrard Street,

Vancouver, B.C.

CANADA V6Z 1 Y6

Tel: (604) 806-9116

Email:uhri@cfenet.ubc.ca

Word Count: 1,517

Tables: 1

Revised: February 4, 2007

Running head: Supervised injection facility use and employment

Key words: employment; supervised injection site; injection drug use 


\begin{abstract}
A supervised injection facility (SIF), where individuals can inject drugs under medical supervision, opened in Vancouver in 2003. The scientific evaluation of the SIF has demonstrated positive public health-related outcomes. However, the influence of supervised injection facilities on individual efforts to reintegrate into mainstream society has not been studied. We examined for a possible relationship between use of the SIF and employment among a cohort of 1090 SIF users using generalised estimating equations (GEE). In a multivariate analysis of factors associated with employment, using the SIF for $\geq 25 \%$ of injections (versus $<25 \%$ of injections) was not statistically significant $(\mathrm{AOR}=1.05,95 \% \mathrm{CI}: 0.88-1.27)$. These findings suggest that the SIF is not having an adverse impact on efforts to seek employment.
\end{abstract}




\section{INTRODUCTION}

The injection of illegal psychoactive drugs continues to be associated with various harms, including the spread of blood-borne disease (1) and harm related to public order and public health (2-3). More than two dozen cities in Europe, Australia and Canada have opened medically supervised safer injection facilities (SIF) to address these harms. SIFs provide a place where individuals are able to inject previously acquired illegal drugs under the supervision of medical staff. Known as Insite, the SIF in Vancouver, Canada is North America's first government-supported, medically supervised SIF. Insite opened in September of 2003 under a legal exemption by the Canadian government (4).

The ongoing scientific evaluation of the Vancouver SIF has demonstrated a number of positive outcomes, which have been summarized elsewhere (5). Despite the demonstrated benefits of Insite, critics suggest that it perpetuates drug use and interferes with efforts to achieve abstinence and hence reintegration into mainstream society $(6,7)$. While there is abund ant research demonstrating the effectiveness of harm reduction initiatives (8), the influence of Insite on injection drug users' (IDU) reintegration warrants ongoing investigation.

One of the crucial components of reintegration into society for IDU is seeking and holding regular employment (9), which can stabilize individuals in structured and productive activity (10), provides a legal source of income and reduces social isolation (11). Employment is often considered an important treatment outcome indicator (10, 
Richardson et al. : Supervised injection facility use and employment

12), and previous studies have found that employment is associated with lowered health risk behaviour, decreased criminal involvement and increased social integration (13-15). However, very few studies, if any, have examined the potential influence of a harm reduction-based intervention on an individual's willingness or ability to obtain or hold a regular job. We sought to determine if use of the SIF has a negative impact on employment rates among a randomly selected cohort of SIF users.

\section{METHODS}

The Scientific Evaluation of Supervised Injecting (SEOSI) cohort is a prospective study of users of Insite that has been previously described in detail (4). Briefly, the sample consists of SIF users who were randomly recruited from Insite for participation in this study and who provided informed consent. During study visits, blood samples for HIV and hepatitis C virus testing were drawn and a questionnaire was administered to elicit demographic and other information. The study has been approved by the University of British Columbia/ Providence Health Care Clinical Research Ethics Board.

The primary endpoint for this analysis was self-reported status of having a job with a regular salary or temporary work in the six months prior to interview. Potential explanatory variables of interest included gender (male vs. female), age, Aboriginal ethnicity, education (less than high school vs. high school or more), unstable hou sing, daily heroin injection, daily cocaine injection, daily crack cocaine smoking, binge drug use, sex trade involvement, residing in the Downtown Eastside (i.e., Vancouver's drug use and HIV epicenter), and regular SIF use. Consistent with previous studies $(16,17)$, we defined "binge drug use" as self-reported periods when drugs were injected more 
frequently than usual, "unstable housing" as living in hotels, hostels, jail or prison, or being homeless, and "regular SIF use" as performing at least $25 \%$ of injections (versus a control group of less than $25 \%$ of injections) at the SIF.

Since analyses of factors potentially associated with employment during follow up included serial measures for each subject, we used generalised estimating equations (GEE) for binary outcomes with logit link for the analysis of correlated data to determine which factors were independently associated with employment in the prior six months. These methods provided standard errors adjusted by multiple observations per person using an exchangeable correlation structure. Data from every participant follow-up visit was therefore considered in this analysis. This approach has been used successfully in previous studies examining correlates of drug treatment access in prospective cohort studies of IDU (18).

As a first step, we examined associations between employment and predictors of interest using univariate GEE. We also fit a multivariate logistic GEE model to adjust for potential confounding and included those variables that were statistically significant at the $p<0.05$ in univariate analyses. Regular SIF use was also included in the final model as a key variable of interest. All statistical analyses were performed using SAS software version 9.1 (SAS, Cary, NC). All p-values are two sided.

\section{RESULTS}

Between December 2003 and December 2005, 1090 individuals were enrolled in SEOSI and all of these were included in the current analysis. Of these, $889(82 \%)$ had at 
least one additional follow -up visit and 731 (67\%) were seen at the most recent follow up. Overall, these participants contributed to 3083 observations during the follow -up period. Among these individuals, the median age was 38.4 (interquartile range [IQR] 32.7 - 44.3), $211(19.4 \%)$ were of Aboriginal ethnicity, and 317 (29\%) were female. Of the 1090 eligible participants for this analysis, 396 (36.3\%) reported having had a regular job at some point during the six months prior to semi-annual follow-up interviews.

The univariate GEE analyses assessing associations between employment and variables of interest are shown in Table 1. Only binge drug use (odds ratio $[\mathrm{OR}]=1.19$, 95\% confidence interval [CI]: 1.01-1.41) was positively associated with employment. Factors negatively associated with employment included female gender $(\mathrm{OR}=0.23$, 95\%CI: 0.17-0.31), Aboriginal ethnicity (OR =0.44, 95\%CI: 0.31-0.61), lower education level $(\mathrm{OR}=0.54,95 \% \mathrm{CI}: 0.42-0.68)$, unstable housing $(\mathrm{OR}=0.56,95 \% \mathrm{CI}: 0.47-0.67)$, Downtown Eastside residency $(\mathrm{OR}=0.66,95 \% \mathrm{CI}: 0.54-0.80)$, sex trade involvement (OR $=0.49,95 \% \mathrm{CI}: 0.36-0.65)$, and daily heroin injection $(\mathrm{OR}=0.80,95 \% \mathrm{CI}: 0.66-0.97)$. Associations between employment and daily cocaine use and employment and daily crack use do not reach statistical significance. Regular SIF use (OR = 1.06, 95\%CI: 0.901.25) was not associated with employment.

In the multivariate GEE analysis also shown in Table 1, binge drug use remained positively associated with employment (adjusted odds ratio [AOR] $=1.27,95 \%$ CI: $1.06-$ 1.52). Factors negatively associated with employment were female gender $(\mathrm{AOR}=0.26$, 95\%CI: 0.18-0.37), Aboriginal ethnicity (AOR = 0.56, 95\%CI: 0.40-0.80), lower education level $(\mathrm{AOR}=0.63,95 \% \mathrm{CI}: 0.50-0.81)$, unstable housing $(\mathrm{AOR}=0.58,95 \% \mathrm{CI} 0.47-0.71)$, 
and daily heroin use $(\mathrm{AOR}=0.81,95 \% \mathrm{CI}$ : 0.66-0.99). Downtown Eastside residency and sex trade involvement did not retain significance.

\section{DISCUSSION}

In the present study we found low rates of employment among SIF users but no statistically detectable relationship between regular use of the SIF and employment as opposed to non-regular SIF use. These data therefore suggest that regular use of the SIF neither interferes with nor promotes facility users' willingness or capacity to seek out and retain formal employment.

These findings indicate that the previously observed benefits of the SIF, including increased use of addiction treatment and reductions in HIV risk behavior (19, 20) have not been undermined by an adverse effect of regular SIF use on employment. One presently unexplored opportunity, which should be the subject of future research, would be to evaluate the impact of incorporating employment services into the range of community resource referrals offered to SIF users. Specialized employment programs designed for substance users have been shown elsewhere to have positive impacts on treatment enrollment, retention and effectiveness $(15,21)$.

Our results also show that there are barriers to employment among users of Insite for females, individuals of Aboriginal ethnicity, those who do not finish high school and those with unstable housing. The effect of socio-demographic characteristics on the vocational activity of IDU is an important result that warrants further examination. 
It is worth noting the drug use patterns of respondents reporting employment. While daily heroin use is marginally and negatively associated with employment, binge drug use is positively associated with employment. This suggests that SIF users who hold regular jobs may concentrate their drug use, which may have implications for the health risks associated with binge drug use, such as increased syringe sharing $(20,22)$, HIV sero-conversion (23), and non-fatal overdose (24).

Our study is limited by SEOSI's observational nature and reliance on self-report, which may introduce both recall and socially desirable reporting biases. Further, while the SEOSI participants have been shown to be statistically similar to the overall cohort of users of Insite (4), it is not possible to generalise the current findings, derived from a specific sample population, to IDU populations more broadly. Lastly, the employment variable used for this analysis is loosely defined as having a regular or temporary job in the six months prior to interview. As such, it is not possible to identify more precise employment patterns among SEOSI participants, which may range from full-time employment or intermittent w ork to persistent unemployment.

In sum, we found no relationship between SIF use and employment, suggesting that SIF use does not interfere with employment, an activity that is strongly associated with addiction recovery. This finding challenges claims that the SIF impedes reintegration into society, supports previous findings that the SIF has not produced any community or health-related harms (5), and suggests that the well-documented benefits of the SIF have not been undermined by adverse effects of SIF use on employment rates. 
Richardson et al. : Supervised injection facility use and employment

Given the small proportion of employed SEOSI participants, these findings further suggest that there may be opportunities to incorporate employment service-related referrals into the resources available at Insite. 
Richardson et al. : Supervised injection facility use and employment

\section{Acknowledgments}

The authors wish to thank the participants in SEOSI and the staff of Insite, the Portland Hotel Society, and Vancouver Coastal Health (Chris Buchner, David Marsh, and Heather Hay.) We also thank the current and past SEOSI staff. We would specifically like to thank Deborah Graham, Tricia Collingham, Caitlin Johnston, Steve Kain, and Calvin Lai for their research and administrative assistance. The evaluation of the supervised injecting facility was originally made possible through a financial contribution from Health Canada, although the views expressed herein do not represent the official policies of Health Canada. The evaluation is currently supported by the Canadian Institutes of Health Research and Vancouver Coastal Health. Lind sey Richardson is supported by the Clarendon Fund, Oxford University Press. Mark Tyndall is supported by a Michael Smith Found ation for Health Research Senior Scholar Award. Thomas Kerr is supported by a Michael Smith Foundation for Health Research Scholar Award and a Canadian Institutes of Health Research New Investigator Award. 


\section{REFEREN CES}

1. Aceijas C, Stimson GV, Hickman M, Rhodes T, United Nations Reference Group on HIV/AIDS Prevention and Care among IDU in Developing and Transitional Countries. Global overview of injecting drug use and HIV infection among injecting drug users. AIDS 2004 Nov $19 ; 18(17): 2295-303$.

2. Kimber J, Dolan K, van Beek I, Hedrich D, Zurhold H. Drug consumption facilities: An update since 2000. Drug and Alcohol Review 2003; 22(2):227-33.

3. Wright NM, Tompkins CN. Supervised injecting centres. BMJ 2004; 328(7431):100-2.

4. Wood E, Kerr T, Lloyd-Smith E, Buchner C, Marsh DC, Montaner JS, et al. Methodology for evaluating Insite: Canada's first medically supervised safer injection facility for injection drug users. Harm Reduct J 2004; 1(1):9.

5. Wood E, Tyndall MW, Montaner JS, Kerr T. Summary of findings from the evaluation of a pilot medically supervised safer injecting facility. CMAJ 2006; 175(11):1399-404.

6. Mangham C. A critique of Canada's INSITE injection site and its parent philosophy: Implications and recommendations for policy planning. J Global Drug Pol and Pract; 1(2):August 7, 2007.

7. CBC News. Police group takes aim at Vancouver safe injection site. CBC News. Sept 12006.

8. Ritter A, Cameron J. A review of the efficacy and effectiveness of harm reduction strategies for alcohol, tobacco and illicit drugs. Drug and Alcohol Review. 2006 [cited August 14, 2007]; 25(6):611. Available from: http://www.informaworld.com/10.1080/09595230600944529. 
Richardson et al. : Supervised injection facility use and employment

9. Platt JJ. Vocational rehabilitation of drug abusers. Psychol Bull 1995; 117(3):416-33.

10. Vaillant GE. What can long-term follow-up teach us about relapse and prevention of relapse in addiction? Br J Addict 1988; 83(10):1147-57.

11. Hills J, Le Grand J, Piachaud D. Understanding social exclusion. Oxford: Oxford University Press, 2002.

12. Magura S, Staines GL, Blankertz L, Madison EM. The effectiveness of vocational services for substance users in treatment. Subst Use Misuse 2004; 39(13-14):2165-213.

13. March JC, Oviedo-Joekes E, Romero M. Drugs and social exclusion in ten European cities. Eur Addict Res 2006; 12(1):33-41.

14. Hser YI, Hoffman V, Grella CE, Anglin MD. A 33-year follow-up of narcotics addicts. Arch Gen Psych 2001; 58(5):503-8.

15. Lundgren LM, Schilling RF, Ferguson F, Davis K, Amodeo M. Examining drug treatment program entry of injection drug users: Human capital and institutional disaffiliation. Eval Program Planning 2003; 26(2):123-32.

16. Wood E, Tyndall MW, Spittal PM, Li K, Kerr T, Hogg RS, et al. Unsafe injection practices in a cohort of injection drug users in Vancouver: Could safer injecting rooms help? CMAJ 2001; 165(4):405-10.

17. Stoltz JA, Wood E, Small W, Li K, Tyndall M, Montaner J, et al. Changes in injecting practices associated with the use of a medically supervised safer injection facility. J Public Health 2007; 29(1):35-9. 
18. Shah NG, Celentano DD, Vlahov D, Stambolis V, Johnson L, Nelson KE, et al. Correlates of enrollment in methadone maintenance treatment programs differ by HIV-serostatus. AIDS 2000; 14(13):2035-43.

19. Wood E, Tyndall MW, Zhang R, Montaner JS, Kerr T. Rate of detoxification service use and its impact among a cohort of supervised injecting facility users. Addiction 2007; 102(6):916-9.

20. Kerr T, Tyndall M, Li K, Montaner J, Wood E. Safer injection facility use and syringe sharing in injection drug users. Lancet 2005; 366(9482):316-8.

21. Reif S, Horgan CM, Ritter GA, Tompkins CP. The impact of employment counseling on substance user treatment participation and outcomes. Subs Use Misuse 2004; 39(13):2391.

22. Fairbairn N, Wood E, Small W, Stoltz JA, Li K, Kerr T. Risk profile of individuals who provide assistance with illicit drug injections. Drug Alcohol Depend 2006; 82(1):41-6.

23. Miller CL, Kerr T, Frankish JC, Spittal PM, Li K, Schechter MT, et al. Binge drug use independently predicts HIV seroconversion among injection drug users: Implications for public health strategies. Subst Use Misuse 2006; 41(2):199-210.

24. Kerr T, Fairbairn N, Tyndall M, Marsh D, Li K, Montaner J, et al. Predictors of non-fatal overdose among a cohort of polysubstance-using injection drug users. Drug Alcohol Depend. 2007; 87(1):39-45. 
Table 1 - Bivariate and multivariate GEE* analysis of factors associated with employment during follow -up $(n=1090)$

\begin{tabular}{|c|c|c|c|c|}
\hline Characteristic & $\begin{array}{c}\text { Unadjusted } \\
\text { Odds Ratio } \\
\left(95 \% \mathrm{CI}^{\ddagger}\right) \\
\end{array}$ & p-value & $\begin{array}{c}\text { Adjusted Odds } \\
\text { Ratio } \\
\left(95 \% \mathrm{CI}^{\ddagger}\right) \\
\end{array}$ & $p$-value \\
\hline \multicolumn{5}{|l|}{ Gender } \\
\hline $\begin{array}{c}\text { (female vs. male) } \\
\text { Aboriginal ethnicity }\end{array}$ & $0.23(0.17-0.31)$ & $<0.001$ & $0.26(0.18-0.37)$ & $<0.001$ \\
\hline (yes vs.no) & $0.44(0.31-0.61)$ & $<0.001$ & $0.56(0.40-0.80)$ & 0.001 \\
\hline \multicolumn{5}{|l|}{ Education level } \\
\hline $\begin{array}{l}\text { Unstable housing } \\
\text { (yes vs. no) }\end{array}$ & $0.56(0.47-0.67)$ & $<0.001$ & $0.58(0.47-0.71)$ & $<0.001$ \\
\hline \multicolumn{5}{|l|}{ DTES $^{\dagger \dagger}$ residency } \\
\hline $\begin{array}{l}\text { Sex trade involvement } \\
\text { (yes vs. no) }\end{array}$ & $0.49(0.36-0.65)$ & $<0.001$ & $0.93(0.65-1.33)$ & 0.707 \\
\hline $\begin{array}{l}\text { Daily heroin use } \\
\quad \text { (yes vs. no) } \\
\text { Daily cocaine use }\end{array}$ & $0.80(0.66-0.97)$ & 0.026 & $0.81(0.66-0.99)$ & 0.041 \\
\hline (yes vs.no) & $0.88(0.73-1.05)$ & 0.152 & - & - \\
\hline \multicolumn{5}{|l|}{ Daily crack use $^{\dagger}$} \\
\hline \multicolumn{4}{|l|}{ Binge drug use $^{\dagger}$} & 0.008 \\
\hline \multicolumn{5}{|l|}{ SIF use ${ }^{\dagger}$} \\
\hline $\begin{array}{l}(<25 \% \text { vs. } \geq 25 \% \text { of } \\
\text { injections })\end{array}$ & $1.06(0.90-1.25$ & 0.465 & $1.05(0.88-1.27)$ & 0.568 \\
\hline $\begin{array}{l}\text { Note: } * \text { GEE }=\text { Generalised } \\
\S \text { h.s. = high school; }{ }^{\dagger} \text { De } \\
\text { interview; }{ }^{\Uparrow \dagger} \text { DTES = Dov }\end{array}$ & $\begin{array}{l}\text { imating Equati } \\
\text { s activities/ ev } \\
\text { w Eastside; }\end{array}$ & $\begin{array}{l}{ }^{t} \mathrm{CI}=\mathrm{C} \\
\mathrm{s} \text { in th }\end{array}$ & 6-month period & ing \\
\hline
\end{tabular}

